\section{OBSERVATIONS ON THE TREATMENT OF ASTHMA.}

By T. L. Pridhan, Esq., Surgeon, Bideford, North Devon. [Continued from $p .435$.

Is the paper published in the Journal on June 9th, I stated that I considered dyspeptic asthma to be, for the most part, under the control of medical treatment, and, according to my experience, by far the most frequent form of the disease. There are some further peculiarities which I have noticed in asthmatic persons, and which I would here name. First, the proportion of cases in men to women, according to my notes, is about eighty per cent. of the former. Secondly, women who are liable to asthma have gout prevailing in their families in a larger proportion than men; whilst in both sexes a number have both these hereditary diseases. Then, again, I have remarked that asthmatic people are, for the most part, gifted with great energy and talents far beyond ordinary people; and in one instance, in a lady, of whom I will hereafter speak, the greatest courage and resolution were evidenced; whilst those afflicted in humble life have been remarkable for intellectual attainments far beyond their station. It has not been unfrequently the case that I have seen persons, as soon as an attack of asthma is over, turn at once to abstruse subjects, to which the peculiar bent of their minds has been directed: and they generally excel in whatever subject of study they are disposed to follow.

I now proceed to the further evidence of cases which have been treated by me under the sedative and strict dietary system; and in doing so, I think I cannot give stronger proof of its efficacy than by quoting communications from patients them. selves, as evidence of the relief they have obtained, and the life of comparative ease and comfort to them after adopting the system. But, before I go further, I would remark on the absolute necessity of procuring the best prepared extracts, which form of medicine I have invariably used for the purpose required. I have more than once been disappointed in my treatment, when my prescriptions have been sent to ordinary druggists, with whom sufficient care has not been taken in this matter; therefore I strongly advise medical men to procure their extracts from, or send their prescriptions to, some known first-rate practical chemist, whose reputation greatly depends on the purity of his chemical preparations. Genuine extracts retain for a long time their distinctive odour, remain moist, and do not mildew. The sedative extracts which I have generally used are those of henbane, conium, belladonna, and stramonium, gradually increasing their doses, and frequently substituting one extract for another, as symptoms appeared to demand.

It is not my intention to enter into the more scientific department as to the supposed causes and effects of this mysterious and capricious disease, so ably treated of in the pages of this JoURNAL by Dr. Hyde Salter, whose remarks I have read with much interest; my object is simply to record my remarks on the history of cases as reported ky my patients, together with observations made by myself during my professional attendance, which may, I trust, lead to the mitigation of sufferings. My own opinion is, that it is impossible, from the present know. ledge we possess, to come to the real causes of the disease in asthma ; but still I trust practical observations may be valuable, inasmuch as they may lead to scientific researches, not only as regards the state of the blood in asthmatic patients, but also as regards the peculiar expectoration which is thrown off, through the medium of the lungs, in the different forms of the disease, which appears to me to be Nature's effort for relief; for it is my strong impression, as I have before stated, that it is in the blood that the secret lies, as, the more healthy is the state of the powers of digestion, so in proportion is the freedom of the patient from disease in dyspeptic asthma. Then, again, as regards persons being affected in certain localities whilst perfectly free in others, may not the peculiar state of the atmosphere add impurities to the blood in some districts, whilst in others a more congenial atmosphere will lessen, and in some instances entirely remove, the impurity which exists in the circulating fluid in those who are predisposed to the disease by hereditary causes? I have, apparently, seen several instances of this kind, which I will hereafter name.

I will now proceed to record the history of cases of dys. peptic asthma.

CASE II. In the year 1855 , I was requested to visit a clergyman, upwards of seventy years of age, from the north of England, who had been residing in this town for some weeks, for the benefit of his health. I had frequently remarked him in the streets ; and not knowing the exact history of his case, I considered he was in the last stage of consumption, so ema. ciated, so feeble and distressed, did he appear. I think I never saw any one walking at large so emaciated. I learned from him, that he had been afflicted with asthma for ten years, that during that time his clerical duties had been suspended, and that, in fact, he was quite a martyr. In this time of his affliction, he had sought every possible advice, both in London and in the country, but without any material benefit or relief; the general opinion given him was, that he would never recover, and that he must bear his affliction as best he could. He was not able to lie down in bed; and, for years, every night he had anticipated death before the morning came, when, however, a copious heavy expectoration would with difficulty be thrown off from the lungs, and as the day advanced he became somewhat relieved, was then dressed, and passed the remainder of the day in great discomfort. Having inquired into his mode of living, I was told pretty nearly as follows:-At six in the morning, he had a cup of strong coffee; at nine, he had tea or coffee, toast, eggs, or a chop; he lunched at one, generally on bread, cheese, and porter; he had a substantial dinner, with porter and wine, and a fair quantity of port-wine after dinner; he had tea or coffee in the evening, as well as supper afterwards. My remark was, "And for all this amount of nourishment, you are as thin as any human being can well be." He replied, "I have been invariably told that, without such support, I cannot live a month; and I take it to make up for the large amount I expectorate in the morning." I examined his chest, and found neither tubercular deposit nor any lesion of the lungs; but evidently, from the very clear sound emitted on percussion, the lungs were emphysematous, particularly under the right clavicle, whilst lower down a dull sound was emitted. In the morning, the pulse was seventy in a minute, but as night came on it rose to ninety or a hundred. His tongue had a very morbid coatlarce, with fissures in it; his stomach was generally distended, and, though he ate so much, he had never any great desire for food; his bowels were irregular; the secretions dark; the urine was loaded with a pink deposit. At the conclusion of my first visit, I surprised him by saying, "You will considerably improve in health under the treatment which I intend to adopt, and, although your age is such, I should not be surprised at your one day being in harness again." His reply was, "That is utterly impossible; my disease has taken such hold on me for so many years." He further said, " he looked forward to nothing but death, and he often prayed to be released from his sufferings." I went on to remark that, if my treatment was to benefit him, seeing it was an extreme case of dyspeptic asthma, he must make up his mind to one thing, and unless it was fully carried out, he must not expect to derive any good result; that was, he must eat just one-fourth of what he was daily in the habit of taking, and, in addition, his food must be weighed, and taken as regularly as the clock struck. His reply was, "If that be your plan, you will soon shorten my days." I begged him to try it for one week, which he at length acceded to. I com. menced my treatment on the 23rd of April, by giving an alterative dose of blue-pill, and a saline aperient. I then ordered three grains of the extract of henbane four times a day, and the same system of dietary as prescribed in my first case, allowing him, in the form of animal food, only two ounces of it twice a day. The result was, that at the end of a week he was able to lie down in bed and sleep several hours; his morning expectoration had lessened considerably ; his appetite improved; his tongue cleaned; the distension at his stomach lessened; the urine was clear; his spirits lightened; and he could exert himself with much more ease. He was now fully satisfied that the plan had so fur succeeded; but his great fear was that he should be starved, by reason of so small a quantity of food being allowed him. At the end of ten days, I substituted the extract of conium for that of henbane, ordering him four grains four times a day. From this time, he improved rapidly until he left the town to return home, on the 14th May. On the 19 th June, he wrote me from London, where he was staying with some friends: "I cannot be sufficiently thanliful for the comparative ease and comfort which, through God's blessing and your skilful management, I have now enjoyed for the last six weeks. The weather has been most unpropitious, notwith standing which, I have not entirely avoided the cold; my nose is rather 'stuffy' from its effects, but no symptoms of asthma have yet appeared, and I trust, by my strictly adhering to your regimen, I may be spared any return." On the 30 th June, he wrote, from his home in the north of England-" I find the air here much keener than in Bideford or in London, and it has come chiefly from the east. I cough a little in the morning, on 
first waking; but I have felt nothing like asthma. I have adhered very generally to your rules, with only the addition of more bread at my breakfast and tea, which you have allowed me. My secretions appear all right. I am, as you saw me, almost a skeleton; but I am in hopes, however, that the wholesome food which I get here will be beneficial." I may remark here, that the months of May and June, in 1855, were unusually cold, the east winds generally prevailing. On the 12th July, my patient wrote: "I am perfectly free from asthma: my appetite is very good, and I greatly desire that my daily allowance may be increased; and the number of my pills, I think, may be reduced." I now ordered five grains of the extract of conium three times a day, and increased his daily allowance of food a little, keeping strictly to the hours of taking it. On the 7 th December, my patient informed me: "Notwithstanding the severity of the cold, and the dampness of the atmosphere, I am quite free from asthma. I now take my medicine only twice a day; it appears to have a wonderful effect. I am able to lie down in bed all night; and I sleep six or seven hours at a time, and feel no difficulty in breathing, and I trust this winter I shall be able to remain at home without a return of my fearful disease." On the 1ith December, he wrote to say he was still going on well-_" Some days since, I im. prudently exposed myself too much to the cold and damp, and was consequently seized with a severe shivering fit, and afterwards fever. I was confined to my bed for forty-eight hours; but no asthma made its appearance. I weighed myself last week; and, notwithstanding my late attack, I found I had gained seven pounds in weight since the previous weighing."

Since the date of the last letter, I have occasionally heard from my patient, who still applies to me for advice whenever his complaint, from any imprudence in diet or irregularity, threatens an attack; and, to make my prediction true, I hear he has occasionally resumed his parochial duties as rector of his parish.

CASE III. The third case of dyspeptic asthma was also in a clergyman, whose appearance was very different from that of the last, he being stout and lethargic. He came to be under my care from the county of Sussex in 1856 . He had been aftlicted for seven years, and his difficulty of breathing was constantly on him whilst awake, particularly after a full meal. On examination, I found his lungs greatly oppressed, and dull on percussion; his heart's action was very feeble and slow; his tongue coated and brown; his stomach greatly distended with flatus, which appeared to distress him greatly; the urine was loaded; he was unable to lie down in bed, and had heavy expectoration in the morning. He still performed his parochial duties, though with the greatest difficulty. Having cleared out the bowels by means of an aperient, I placed him on the sedative and strict dietary system, giving three grains of the extract of conium four times a day, with a pill every other night of two grains of each of the extracts of taraxacum and simple aloetic pill.

He came under my medical care on the 1st September. On the 8 th of the same month, I had the following bulletin from him. "My health improves rapidly under your mode of treatment, and I was able yesterday to repeat the responses at church with ease to myself; and I took a walk without feeling the least oppressed in my breathing or fatigue to myself. I have been afflicted with asthma for more than seven years, and have consulted several eminent physicians without anything like the relief which I even now enjoy. A week only has elapsed since I consulted you ; and yet, I am thankful to say, my chest is so much relieved, that I am able to walk several miles without being obligea to rest in order to fetch breath." On the 18th September, he wrote:- "By this time you will be anxious to know how I am going on. The weather has been certainly very fine and clear since I commenced your mode of treatment; but many a year has elapsed since I have had such freedom from pain. On 'Thursday last, I walked up a steep hill of half a mile without stopping once; and, on the following day, I bore the fatigue of a long journey into Sussex, without finding my chest at all oppressed. Last Sunday was the grand criterion; and I can assure you my voice was remarkably clear, and my chest but scarcely influenced by the enemy." On the 2nd October, he wrote:- "My health, on the whole, is very satisfactory. Since I last wrote to you, the weather has been very cold and stormy; notwithstanding which, I have breathed more freely than I have for many a year, and I now go about the active duties of my calling with confidence."

Another letter, a month afterwards, tells me he is quite well since which time I have had no communication with my patient, but I learn from his friends that, thinking that he had remained 580 so long free from complaint, he might with impunity return to his former way of eating and drinking whatever came in his way, he has consequently since experienced returns of his complaint, as might naturally be expected; for, as I have be. fore stated, an asthmatic patient, who inherits asthma, can never with impunity eat and drink as other people; and, although I gradually increased the amount of support taken in this case, yet the patient was not satisfied, but allowed his inclination to overrule his better judgment.

The above case must be admitted to be strong proof how much the disease is influenced by the manner in which the office of digestion is performed, and how much the patient has it in his own power to live a life of comparative ease and comfort.

It is my intention to give further proof of the success of this treatment in my next paper.

[To be continued.]

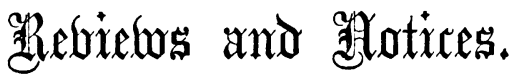

On Obscure Diseases of the Bratn and Disorders of the Mind : their incipient Symptoms, Pathology, Diagnosis, Treatment, and Prophylaxis. By Forbes Winsiow, M.D., D.C.L.Oxon. Pp. T21. London: Churchill. 1860. [Continued from page 501.$]$

A Dispassionate feeling on the part of the general public-at any rate on the part of the educated classes, to say nothing of N the importance of an intelligent interest regarding insanity, is one great essential towards progress. But the medical profession must first look at home before it can with justice reflect upon shortcomings in other quarters. The pathology and morbid anatomy of the nervous system, and of the brain especially, have been much neglected. A reference to the Transactions of the Pathological Society will prove how much and how little has been really done in advancing cerebral pathology. Let any one observe the perfunctory slicing of the brain in most post mortem theatres, and then let him say what is to be expected from that kind of pathological examination of an organ so complicated and diverse in its constituents, so massive and at the same time so delicate in structure.

Dr. Winslow is evidently deeply impressed with this great want of pathological knowledge-his experience has shown him where the stumbling block lies-and his earnest hope evidently is that he may excite the ambition of his readers. Dr. Winslow says :-

"A vast and unexplored region of scientific inquiry is open to the zealous, courageous, and enterprising philosopher, who investigates the subject of chemico-cerebral pathology. Much o untrodden ground exists in association with this deeply interesting and hitherto neglected subject. Any attempt to unravel, $\mathrm{O}$ by the aid of chemical science, psychical and nervous phe. nomena so abstruse, may prove, for a time, unproductive of $N$ any practical results; nevertheless, some advantage must accrue from these investigations."

The anatomist and the chemist must work hand in hand. Every day chemical discoveries are being made, and chemical $\mathcal{O}$ processes are being simplified. Why should photographical be $\mathrm{\omega}$ so much in advance-as it undoubtedly is-of pathological 0 chemistry? The practical physician naturally shrinks from 0 the tedious manipulations of the laboratory, but from him the chemist must receive inspiration. The title of Dr. Winslow's \& work forbids one to expect that the pathological anatomy of the brain should be fully treated of therein. There will be 0 found, however, in the sections devoted to the subject not only $\mathbb{\mathbb { D }}$ much to set the reader thinking, but, of most valuable information, an earnest given of what may be looked for in the volumes promised to succeed. In thus endeavouring to promote accu. rate pathological investigation, Dr. Winslow entitles himself to 8 the active support of the rising school of pathological anatomists.

Having thus, as we hope, seconded the leading of Dr. Winslow in his endeavours to promote accurate pathological

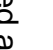

\section{o}

